\title{
FRESHLY COMPRESSED FIBER REINFORCED CONCRETE
}

\author{
الخرسيانة المسندة بالألياف و المضينوطة وعي في الحالة الطنازجة
}

A. A. Al-Tuhami, and M. H. Seleem

Faculy of Engineering, Zagazig University

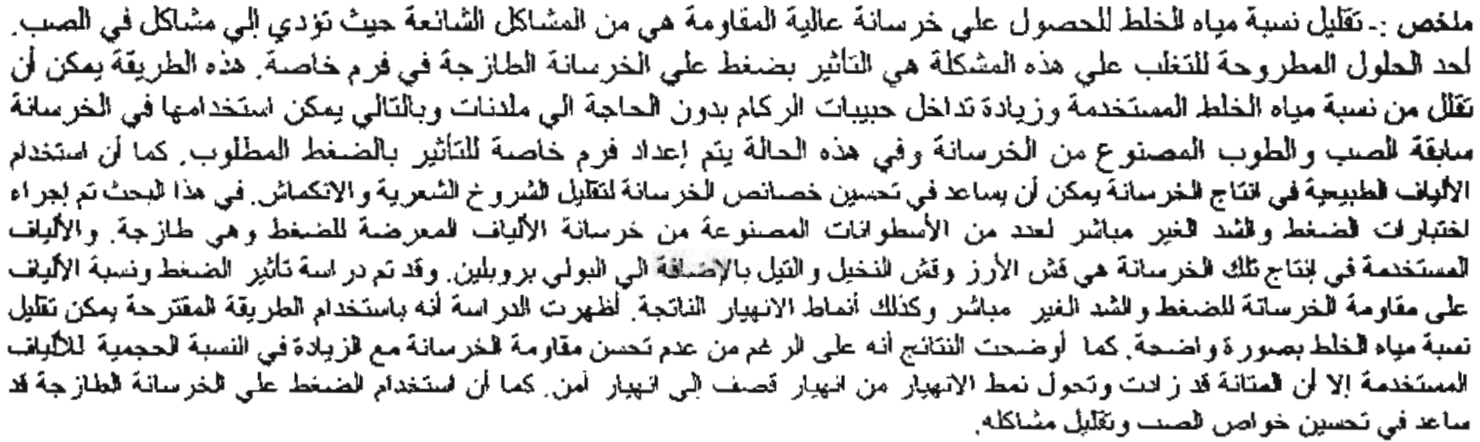

\section{ABSTRACT}

One of the most famous problents in concrete technology is redicing the water cement ratio (w/c) to obtain high strengih concrete. An innovalive method 10 do so is to compress the freshly caste concrelc under pressurc using special lorms. The melhod remarkably reduces the water-cement ratio through expelling the excess water from the mix. In addition, compressing the freslnly cast concrete resulting in packing the concrete particles together which reduces the voids and increase the interlocking between aggregates. Consequently, the resulting concrete from this process has higher compressive strenglh, lower water-cement ratio. In addition, the uses of natural fiber add a new green product, or in other words environmental friendly concrete composites can be produced througly recycling the natural fibers instead of burning or adding a burden to the already exhausted environment. II this researcl, a comprehensive testing program is performed to study lle effect of using natural and artificial fibers in improving the strength properties and tailure modes of freshly cast concrete. Different types of fibers were used including rice slraw, llax fibers, date palm fibers, and polypropylene. Also, the studied parameters included the fiber volume liaction and the pressure applied into the fresh concrete. The evaluation was based on measuring compressive strength, tensile strength and mode of failure of the produced fiber reinforced concrete. Results indicated that although the used fibers didn't enhance either the compressive or the tensile strengths, they change the mode of failure to be safe.

Keywords: freshly compressed concrete, fiber concrete, natural fiber, polypropylene fibers; strength, mechanical propertics.

Accepled June 3, 2007 


\section{INTRODUCTION}

Fiber reinforced concrete (FRC) is Portland cement concrete reinforced with more or less randomly distributed fibers. In FRC, thousands of small fibers are dispersed and distributed randomly in the concrete during, and thus improve concrete properties in all directions. Fibers help to improve the post peak ductility performance, pre-crack tensile strength, fatigue sirength, impact strength and eliminate temperature and shrinkage cracks [1-6]

Several different types of fibers, both man-made and natural, have been used to reinforce the cement-based matrices. Use of natural fibers (NA) in concrete precedes the advent of conventional reinforced concrete in historical context. The choice of fibers varies from syntlectic organic materials such as polypropylene or carbon, synthetic inorganic such as steel or glass, natural organic such as cellulose or sisal to natural inorganic asbestos. Currently the commercial products are reinforced with steel, glass, polyester and polypropylene fibers. The selection of the type of libers is guided by the properties of the fibers such as diameter, specific gravity, young's modulus, lensile strength etc and the extent these fibers affect the properties of the cement matrix

Historically, natural vegetable fibers or simply NF are empirically used to reinforce several construction materials, as the case for the production of textile material. However, only recently scientists start to study the application of this type of fiber as concrete reinforcement [7]. NF can be obtained at a low price using locally available manual labor and adequate techniques. These fibers are usually known as unprocessed NF. However, NF can be chemically or mechanically processed to enhance their properties. NF are readily available in large quantities in many countries and they represent a continuous renewable source. At the end of the 1970s, a systematic evaluation of engineering properties of NF is performed, including the performance of Portland-cement-based composites containing these fibers. Even the results of flexural and impact strength are encouraging, the deficiencies related to the long-term performance of NF reinforcement are also reported [7]. These deficiencies are related to a degradation of the fiber by the alkaline cement paste environment and the increase of fiber dimensions related to variations in humidity [8].

As the NF are agriculture waste, manufacturing natural product is, therefore, an economic and interesting option. Therefore, from the materials science point of vicw, there is growing interest in green, environmentally friendly materials. If we consider composites, one of solutions can be use of natural libers instead of more traditional glass and carbon fibers. The possible advantages of such natural fiber could be

- Lower pollution level during production;

- Energy necessary for fiber production is lower than that of synthetic fibers like glass or carbon;

- Lower cost.

- However, all these previous statements shou'd be supported by quantitative analysis.

- Natural fibers are renewable resources;

- Natural fibers in composites can compete with synthetic fibers by Lower density;

- Healthier in use due to their natural origins;

- Less abrasive to the processing equipment. 
- Low density is the main point why NFC is interesting in automotive sector.

Production tines are designed to suit different environments [9]. A comparison between epoxy polymer concrete reinforced with NF, un-reinforced and reintorced with synthetic fibers is made by Reis[1]. Coutts [10] used Banana fibers as reinforcement for building products. Wood pulp and other NF. were gained inroads as reinforcing materials in cement-based composites. Small amounts of NF had been shown to be effective in preventing plastic shrinkage cracking in flat work and in reducing cracking and expansion due to deleleterious reactions such as alkali silica reaction and freeze/thaw cycling [II]

Rice straw, flax and palm fibers products are produced by large amount in Egypt. These products considered as an environmentally friendly alternative of synthetic fibers. Loss of workability and blockage of fibers during casting are the main problems that appear when using fibers in concrete. An innovative method to do so is to compress the freshly caste concrete under pressure using special forms. The method remarkably reduces the water-cement ratio through reducing the $w / \mathrm{c}$ ratio and expelling the excess water from the mix. In addition, compressing the freshly cast concrete resulted in packing the concrete particles together which reduces the voids and increase the interlocking between aggregates. The technique is applied on four types of fibers, three from which are NF and the other is polypropylene fibers. The evaluation is based on measuring the mechanical propertied of the compressed concrete and studying the modes of failure.

\section{EXPERIMENTAL PROGRAM}

An experimental program was designed to investigate the effect of natural and artificial fibers composites on the mechanical properties of freshly compressed concrete. The materials used in fabrication of all test specimens are Jocally available materials. Type I ordinary Portland cement and ordinary silficeous sand of $100 \%$ passing ASTM sieve No.4 were used. The coarse aggregale used was gravel having maximum nominal size of $14 \mathrm{~mm}$. The ratio of coarse aggregate to fine aggregate was 2:1. The cement content was kept equals $450 \mathrm{~kg} / \mathrm{m}^{3}$ and water/cement ratio of 0.35 . Four types of fibers were used in the present work (Natural and artificial). The natural fibers are, flax fibers, date palm fibers and rice straw, while the artificial libers are polypropylene. For all types, the fiber length is $25 \mathrm{~mm}$. Each type is added by different volume fraction, $v_{f} \%$, as shown in Table 1.

Table 1: Variables investigated in this work

\begin{tabular}{|c|c|c|}
\hline $\begin{array}{l}\text { TYPE OF } \\
\text { FIBERS }\end{array}$ & $V_{F} \%$ & $\begin{array}{l}\text { MIX } \\
\text { CODE }\end{array}$ \\
\hline Flax fibers & $0.79,1.58,2$ & $\mathrm{Fl}, \mathrm{F} 2, \mathrm{~F} 3$ \\
\hline Rice straw & $\begin{array}{l}0.93,187, \\
2.8\end{array}$ & $\begin{array}{l}\text { RS1, RS2, } \\
\text { RS3 }\end{array}$ \\
\hline Date palm fibers & $\begin{array}{l}1.24,1.88, \\
2.5\end{array}$ & $\begin{array}{l}\text { DPI, DP2, } \\
\text { DP3 }\end{array}$ \\
\hline Polypropylene & $\begin{array}{l}2.88,3.42, \\
5.77\end{array}$ & $\begin{array}{l}\mathrm{PP} 1, \mathrm{PP} 2, \\
\mathrm{PP} 3\end{array}$ \\
\hline
\end{tabular}

The premix technique was used for the fabrication of all test specimens. The dry materials including cement, gravel and sand are mixed together in the dry state until they are thoroughly blended. The water is then added to the mixture. After getting complete workable mix, the fibers are then added gradually to the mix and the composite is mixed by hand and kept carefully to minimize fiber damage.

The mixed fiber reinforced concrete is transferred to a specially placed steel mould designed to produce the freshly compressed concrete. The steel mould used in producing the freshly compressed concrete comprises 
the following:

i- A circular steel base plate with a group of six symmetrically arranged holes is prepared first.

ii- A group of threaded bars with suitable length and diameter are passing through the prepared holes and protruded vertically, Fig. 1.b.

iii- A cylindrical mould is placed just over the base plate with the threaded bars symmetrically arranged around it. It should be noted that this mould has an internal gentle slope to allow easy expulsion of the compressed specimen.

iv- The concrete or fiber concrete is then cast in the cylindrical mould, Fig. I a.

v- A solid steel cylindrical cover, as shown in Fig. 1.b, c, is then placed over the freshly cast concrete, with the threaded bars passing through a specially prepared holes, which are coincident with those made in the base plate and the nuts are placed over the steel cover.

vi- The fresh concrete is then compressed by turning the nuts inward and tensioning the threaded bars using wrench torque. The load applied on each specimen $(100 \mathrm{~mm}$ diameter and $200 \mathrm{~mm}$ length) is 12 tons.

vii- After 24 hour, the nuts are untied, the cylindrical cover is removed and the compressed concrete specimen is then extracts from the mould using the solid cylindrical steel shown in Fig. I.c.

Three specimens were cast from each mix to take their average value. After casting by 24 hours, the specimens were removed from the moulds and placed immediately in the curing water. The curing time was 28 days. Specimens were left 6 years before testing in order to measure results reflect the real durability of the tested specimens. The compression and indirect tensile test are tests were carried out on cylindrical moulds of $100 \mathrm{~mm}$. diameter and $200 \mathrm{~mm}$ height.

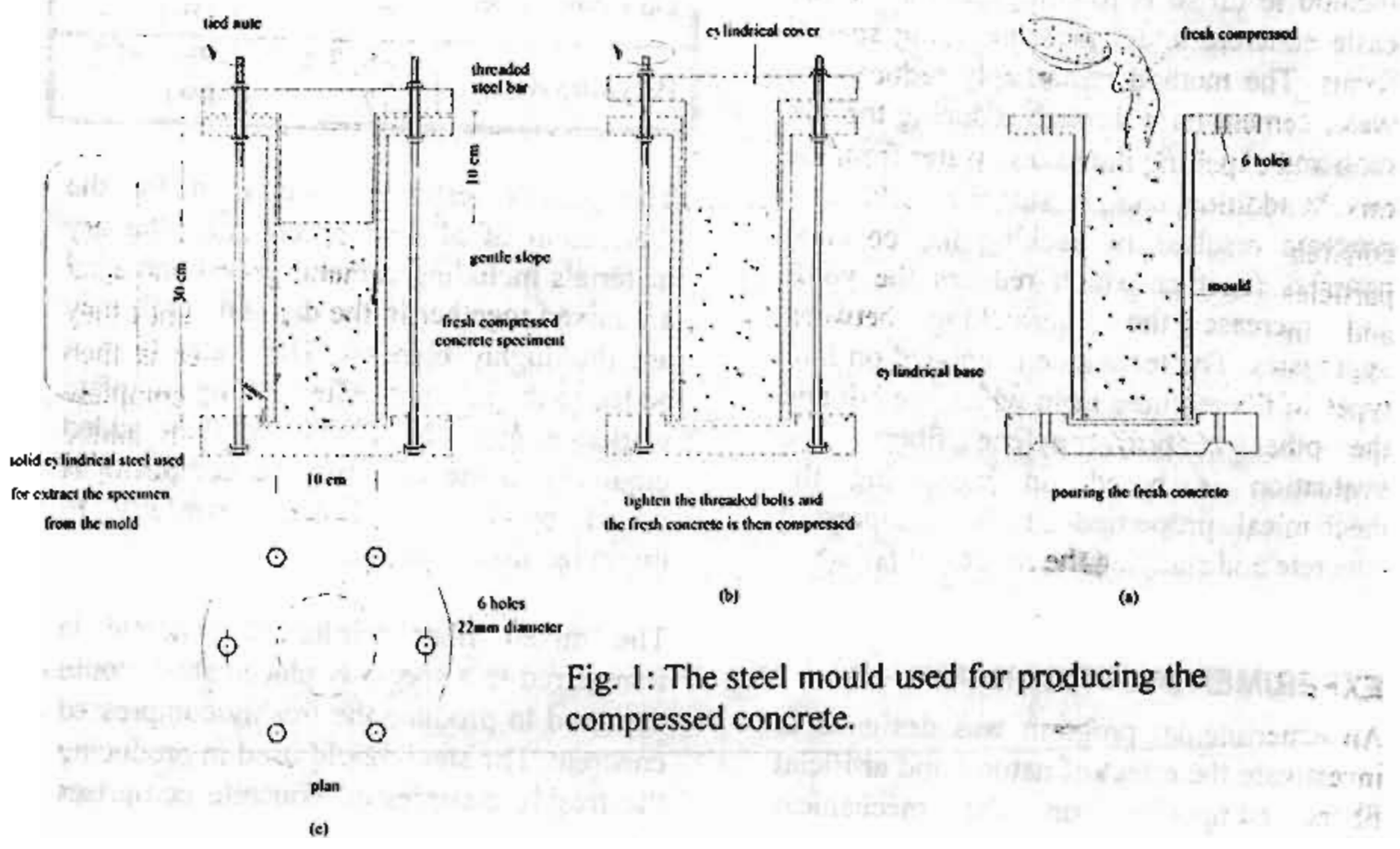


Three of the all test specimens were caste without any fiber. These specimens are tested after 8 days under axial compression. The average ultimate load was $300 \mathrm{kN}$.

Fig. 2 and Fig. 3 show the effect of natural fibers (flax fibers, rice straw and date palm) and polypropylene fiber contents on the compressive strength of compressed concrete. It is clear that the compressive strength decreases with increasing fibers content (either natural or artificial). The data in Fig. 2 shows a linear relation between the content of fibers and compressive strength for natural fiber composites in the form:

$$
\sigma_{\mathrm{c}}=\alpha V_{f}+\sigma_{\mathrm{co}}
$$

Where $\alpha$ is a constant depend on the type of fiber as illustrated in Table 2. The boundary condition for this relation is already satisfied. i.e. wher $V_{l}$ is equals zero the compressive strength is equals that of ordinary concrete, $\sigma_{c a}$.

Table 2: Values of constant $\alpha$

\begin{tabular}{|c|c|}
\hline Fiber type & value of constant $\alpha$ \\
\hline Flax fibers & -6.65 \\
\hline Rice straw & -8.62 \\
\hline Palm fibers & -8 \\
\hline
\end{tabular}

While the data in Fig. 3 best fit the following power relation between polypropylene fiber volume fraction, $V_{f} \%$, and compressive strengih:

$$
\sigma_{\mathrm{c}}=a\left(V_{f}\right)^{\beta}
$$

Where the value of $a$ equals 6258 and $\beta$ equals -1.1

The data in the last two figures also clearly indicate that the highest compressive slrength at different $V_{f} \%$ of natural fibers is recoded by the flax fiber reinforced concrete followed by the date palm fiber concrete, while the lowest strength is recorded by the rice straw concrete. The polypropylene fibers recorded higher compressive strength compared to those of natural fibers at low $\mathrm{v} / \%$. With increasing polypropylene fiber volume fraction, the compressive strength decreases rapidly to reach values less than those recorded by flax fiber reinforced concrete but still higher than those recorded by rice straw and date palm fiber concrete.

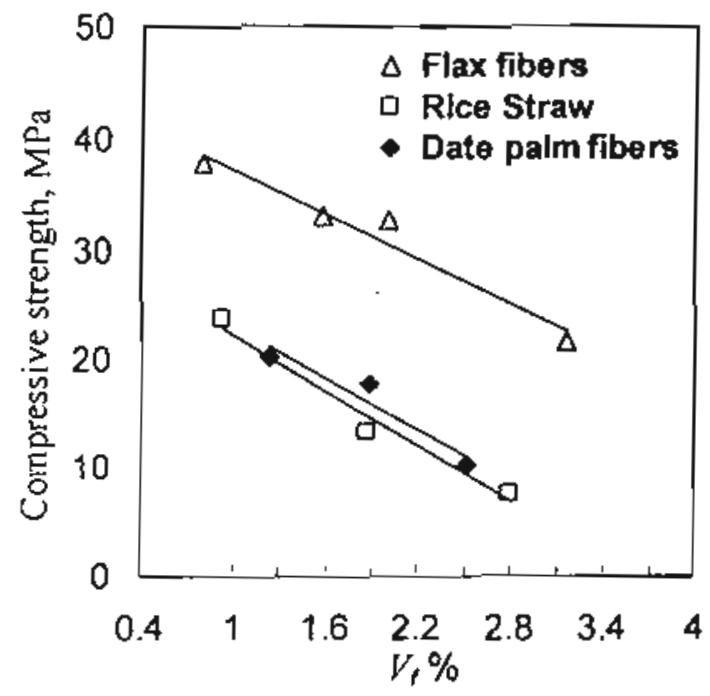

Fig. 2 Effect of natural fiber on the compressive strength of concrete

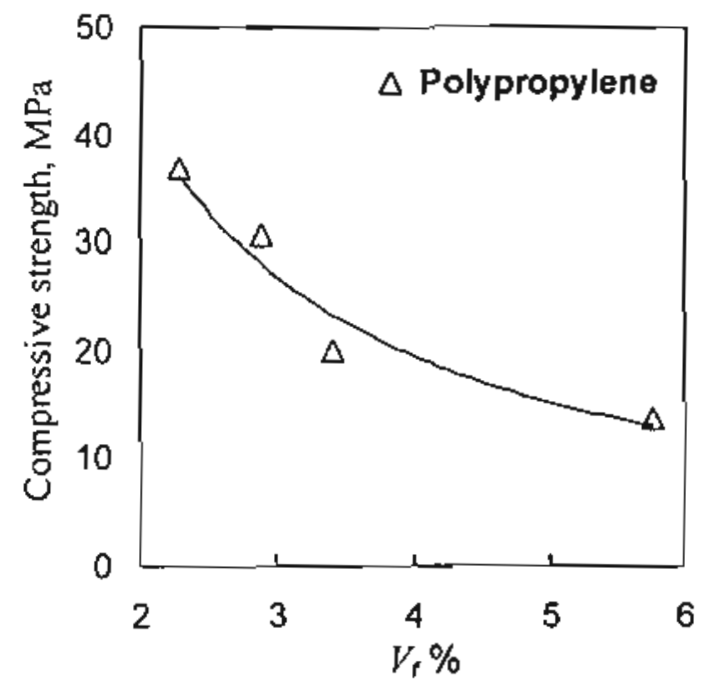

Fig. 3 Effect of polypropylene fiber on the compressive strength of concrete 


\section{32 A. A. Al-Tuhami and M. H. Selcem}

Fig. 4 and Fig. 5 show the effect of $V_{f} \%$ of natural and polypropylene fibers respectively on the indirect tensile strength of fiber reinforced concrete (FRC). The tensile strength decreases with increasing $v_{f}$ $\%$ but the rate of decrease in the flax fiber reinforced concrete is small compared to other types of fibers. On the other hand, polypropylene fiber reinforced concrete results in the highest tensile strength in the range of $\mathrm{v}_{f} \%$ used in the three types of natural fibers.

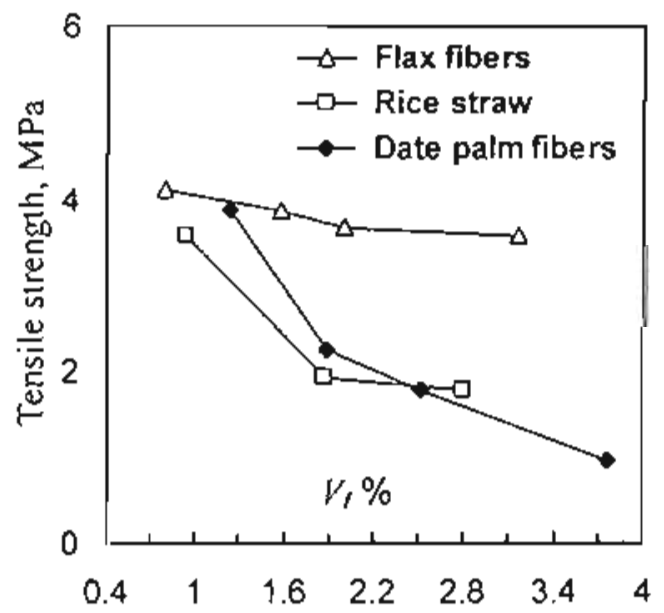

Fig. 4 Effect of natural fiber on the tensile strength of concrete

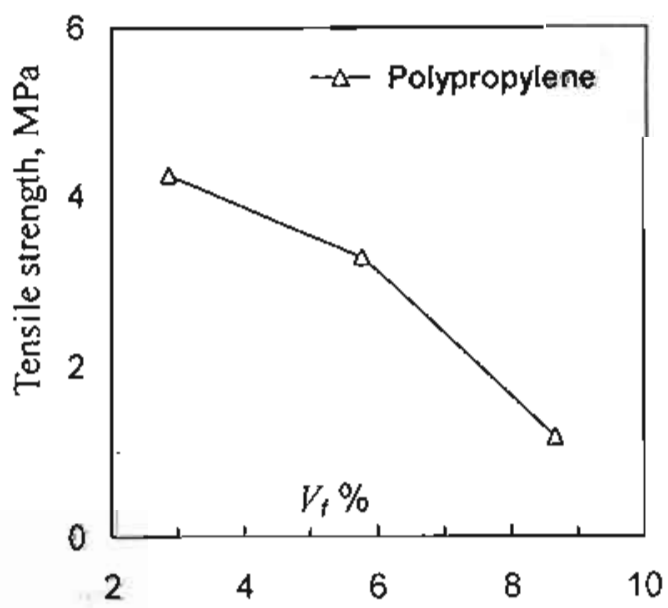

Fig. 5 Effect of polypropylene fiber on the tensile strength of concrete
This trend is followed by the flax FRC and the lowest tensile strength is recorded for rice siraw FCC.

One of the important finding of the present work is the load - deflection behavior of the studied FRC and modes of failure. The loaddeflection curves for the three types of natural fiber (flax fibers, rice straw and date palm fibers) reinforced concrete and that for polypropylene FRC are represented in Fig. 6 to 9.

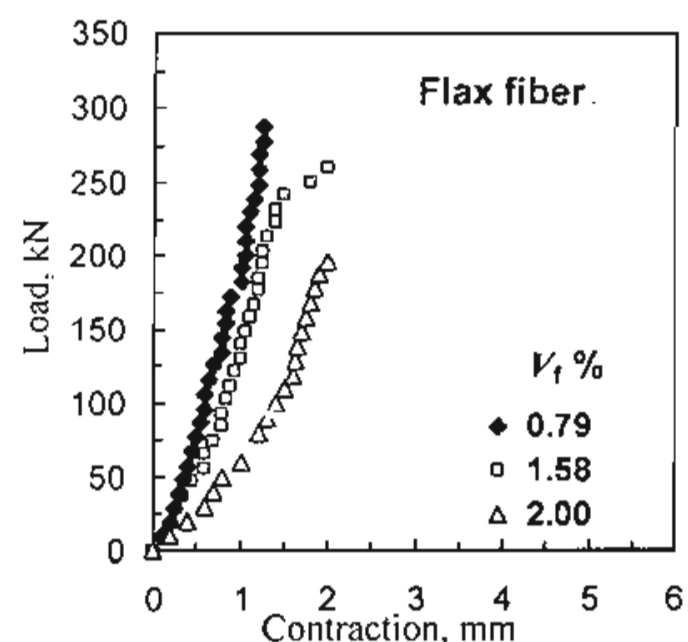

Fig.6 Load contraction behavior for flax FRC

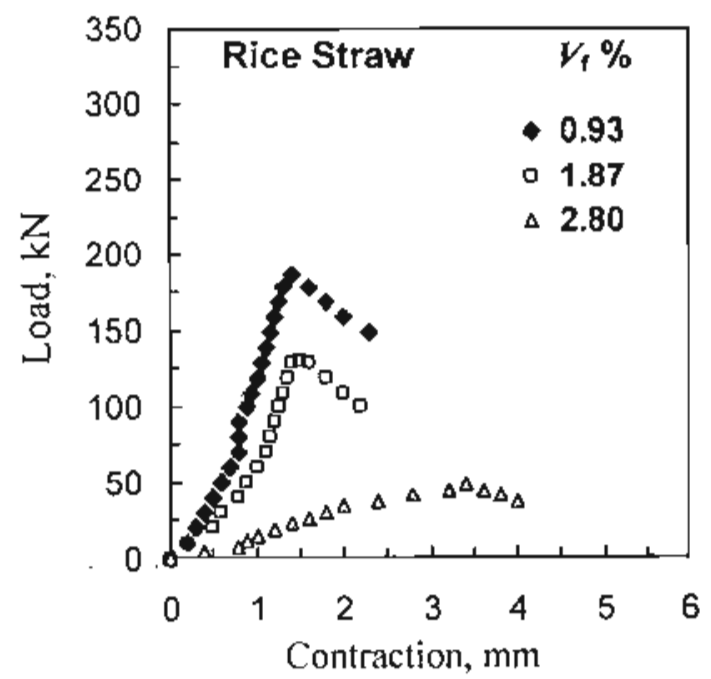

Fig. 7 Load contraction behavior for rice straw FRC 


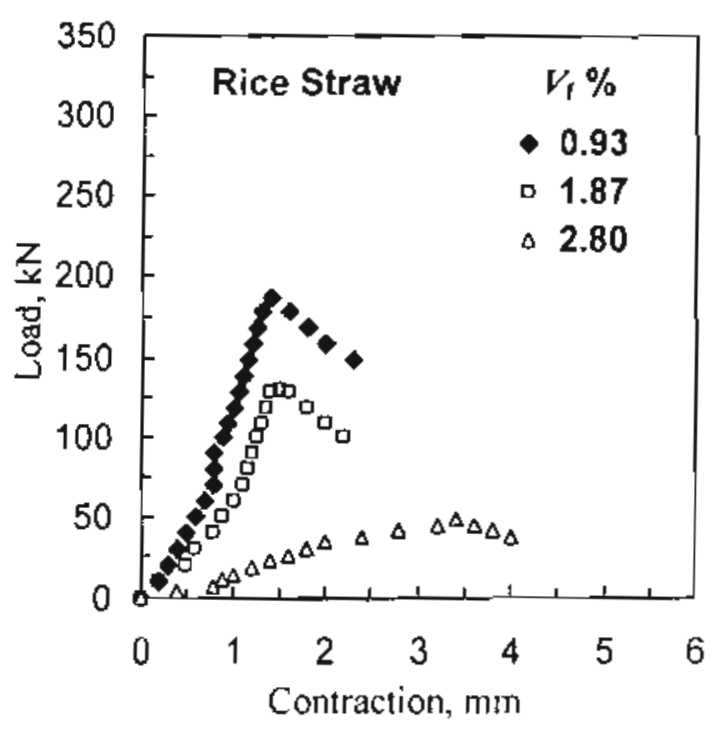

Fig. 7 load contraction behavior for rice straw FRC

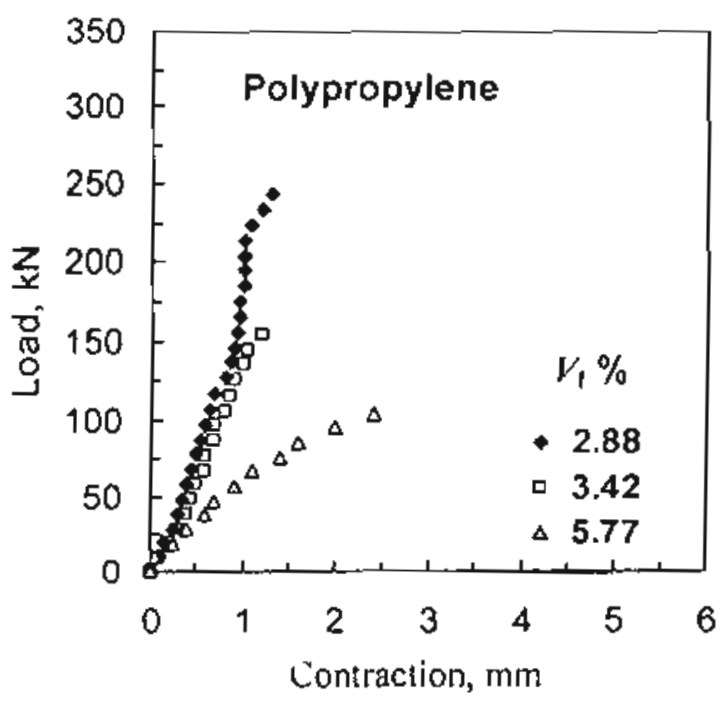

Fig. 9 Load contraction behavior for polypropylene FRC

The figures show that the initial stiffness as indicated by the slop of the ascending portion of the curves is decreased with increasing $\mathrm{v}_{f}$ $\%$. The ascending portion of the curve for the specimen with small $\mathrm{v}_{f} \%$ is almost straight line, whereas the descending curve has almost vanished. At low fiber content, the specinens failed violently and suddenly. The figures also show that the mid-span vertical deflection corresponding to the maximum load increased with the increase in $v_{f} \%$. Rice straw FRC showed more ductile nature raiture compared to other type of FRC. Increasing the fiber volume fraction, altered the failure mode of the test specimens from a brittle to a more ductile failure and the characteristics of failure are completely changed. Modes of failure for the different fibers used in the present investigation are illustrated in Pholos from 1-4. Parts from indirect tensile tested specimens show the distribution of rice straw, palm and flax fiber in the concrete are shown in Photos 5 and 6.
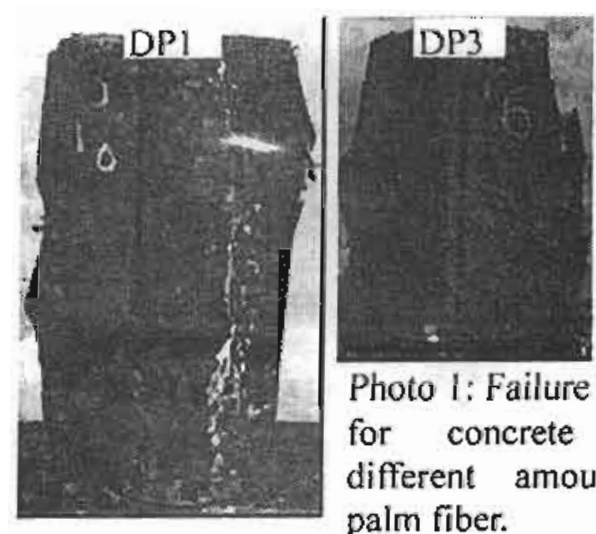

Photo 1: Failure modes for concrete with different amount of palm fiber.
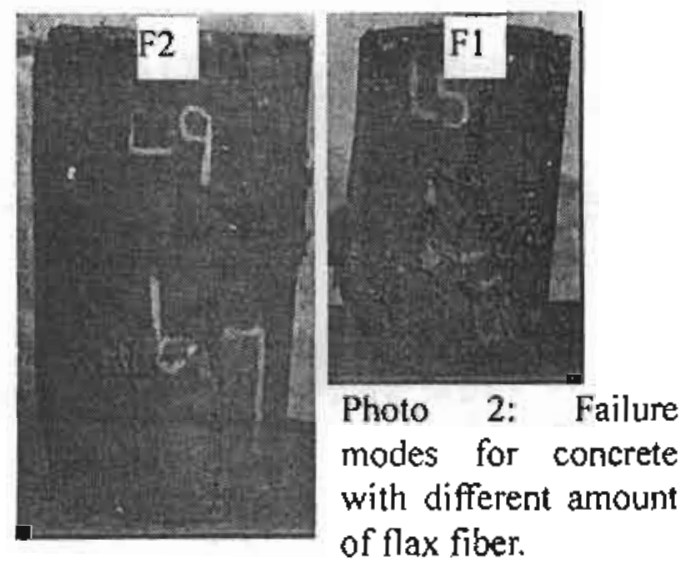


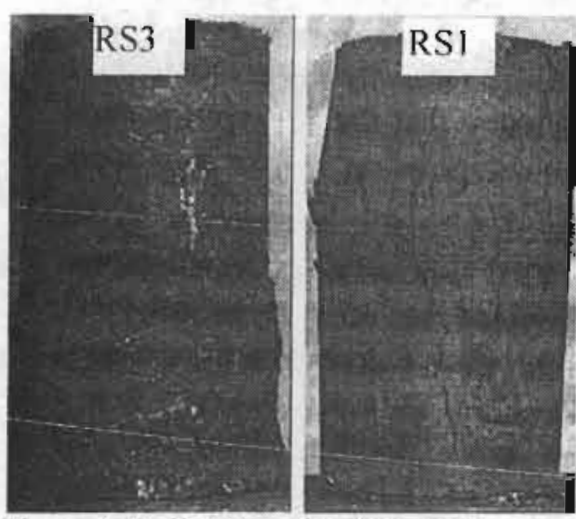

Photo 3: Failure modes for concrete with high and low amount of rice straw fiber.
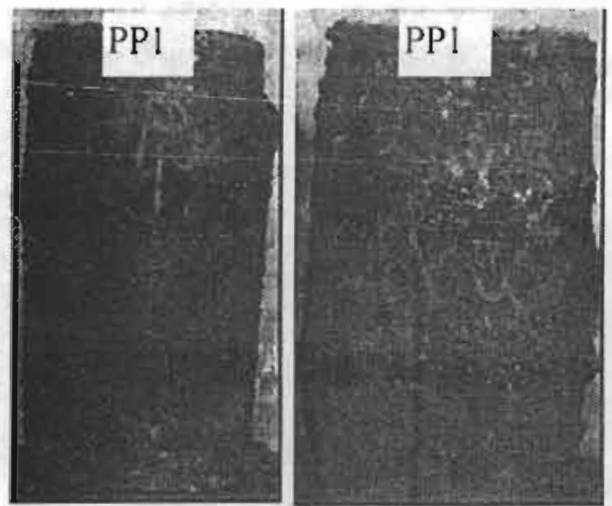

Photo 4: Failure modes for concrete with different amount of polypropylene fiber.
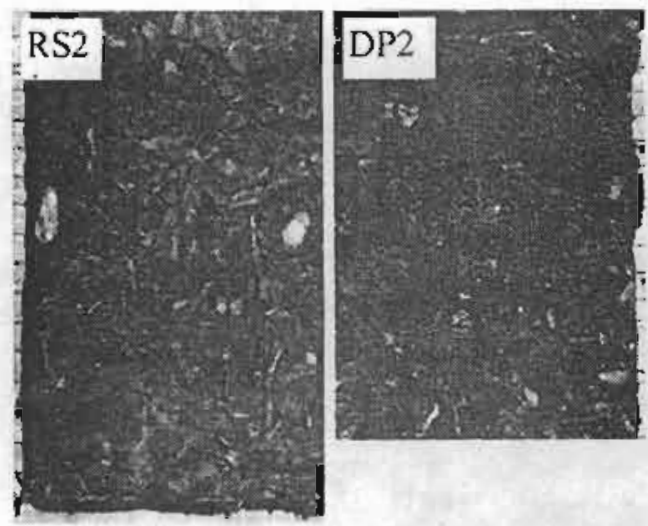

Photo 5: Parts from indirect tensile tested specimens show the distribution of rice straw and palm fiber.

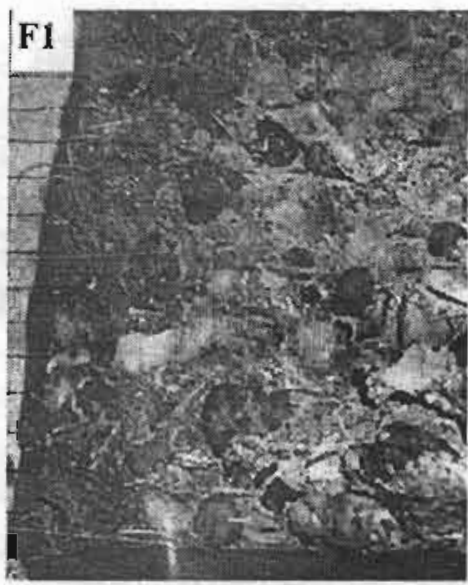

Photo 6: Part from indirect tensile tested specimen show the distribution of flax fiber.

\section{Effect of applied pressure and aging time on the tested specimens}

Specimens were left for 6 years in order to determine the amount of degradation in the natural fibers. It was noticed that, among the natural fibrous concrete specimens, the rice straw fibers give the worst amount of degradation while the flax fiber was not affected. These notices assured through tests.

The effect of applied pressure on the freshly compressed concrete, the samples sawed (photos 7-9) show a smooth compacted clean surface except for the rice straw specimen at the positions of straw only which showed small voids in such positions, photo 8. Even though the big amount of polypropylene fibers used, the pressure applied on the iresh concrete give good compacted sa.nples, photo 9 . 


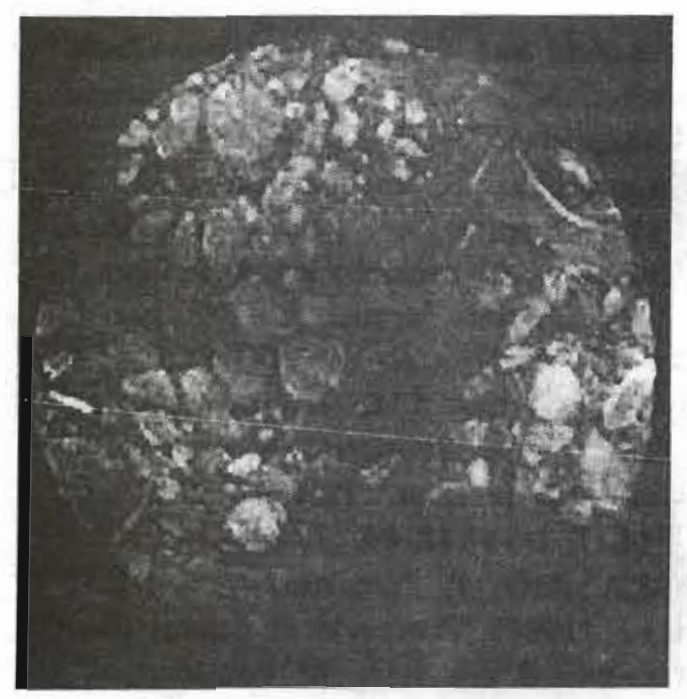

Photo 7: cross-section of specimen with flax fibers, F2 type.

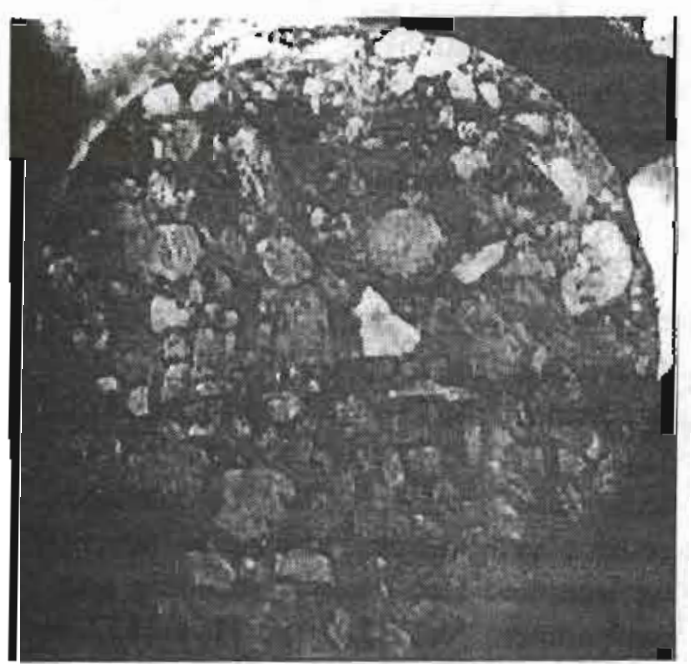

Photo 8: cross-section of specimen with rice straw fiber RS2 type.

\section{CONCLUSIONS}

A suggested technique for reducing water cement ratio and increasing the interlocking between aggregates in the concrete mix is presented. The method is based on compress the freshly caste concrete under pressure

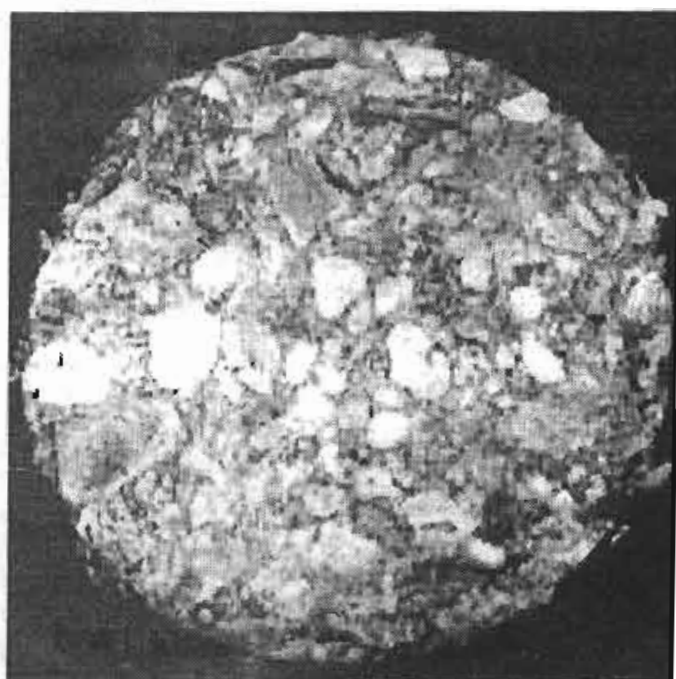

Photo 9: cross-section of specimen with big amount of polypropylene fiber, PP2 type.

using special forms. A comprehensive testing program is perfoniled to study the effect of the use of rice straw, palm and flax natural fibers along with polypropylene artificial fibers in improving the strength properties and failure modes of freshly cast concrete under pressure. The studied parameters included the types and amounts of added fibers and the pressure applied into the fresh concrelc.

The results clearly indicate that the highest compressive strength at different contents of natural fibers is recoded by the flax fiber reinforced concrete followed by the date palm fiber concrete, while the lowest strength is recorded by the rice straw concrete.

The polypropylene fibers recorded compressive and indirect tensile strength closed to those of natural fibers at low fiber content.From the load - contraction curves of all types of fiber concrete, the initial stiffness as indicated by the slope of the ascending portion of the curves is increased with decreasing fiber content. It was noticed that, among the natural fibrous concrete 
specimens, the rice straw fibers give the worst amount of degradation while the flax fiber was not affected. These notices assured through tests. The effect of applied pressure on the freshly compressed concrete, the samples sawed show a smooth compacted clean surface except for the rice straw specimen at the positions of straw only which showed small voids in such positions. One of the most important finding is that the flax fibers have the best potential and environmental replacement of synthetic fibers.

\section{REFERENCES}

[1] J.M.L. Reis (2006)"Fracture and flexural characterization of natural fiber-reinforced polymer concrete", Construction and Building Materials, 20, pp. 673-678.

[2] R.M. de Gutiel rrez , L.N. Diaz, S. Delvasto (2005)"Effect of pozzolans on the performance of fiberreinforced mortars", Cement \& Concrete Composites 27, pp. 593598.

[3] Og"uz AkNn Du"zgu"n *, Ru"stem Gu" I, Abdulkadir $\mathrm{Cu}^{\prime \prime}$ neyt Aydin (2005)"Effect of steel fibers on the mechanical properties of natural lightweight aggregate concrete", Materials Letters, 59, pp. 3357-3363.

[4] R. Brown, A. Shukla and K.R. Natarajan, (2002)"Fiber reinforcement of concrete structures URITC PROJECT NO. 536101, University of Rhode Island September 2002.

[5] Alhozainy, A. M., Soroushian, P. and
Mirza, F. (1996) "Mechanical properties of polypropylene fiber reinforced concrete and the effects of pozzolanic materials.", Cement and Concrete Composites, Vol. 15, pp 85.

[6] Soroushian, p. and Ravanbakhsh, S. (1998)"Control of plastic shrinkage cracking with specialty cellulose fibers." ACl Materials Journal, Vol. 95, No. 4, pp. 429-435.

[7]ACl Committee 544, State-of-the-art on fiber reinforced concrete. ACI manual of concrete practice, Part 5; 1998. p. 544.1R-1-544.1R-66.

[8] M.A. Aziz, P. Paramasivam and S.L. Lee, (1981) "Prospects of natural fiber reinforced concretes in construction", International Journal of Cement Composites and Lightweight Concrete, 3 (2), pp. 123-132.

[9] Poon T., Vitul L., Ampan B. and Wassanai W. (2006) "Sustainable supply chain of construction products and materials: a case study of natural - fiber cement wal! products", CMU Journal, vol 5(2), pp. 153-162.

[10] R.S.P. Coutts, (1990) "Banana fibres as reinforcement for building products, $J$. Mater: Sci. Lett., 9, pp. 1235-1236

[11] C. Juárez, A. Durán, P. Valdez and G. Fajardo, (2007) "Performance of "Agave lecheguilla" natural fiber in portland cement composites exposed to severe environment conditions "Building and environment, Vol. 42, 3, pp 1151-1157. 